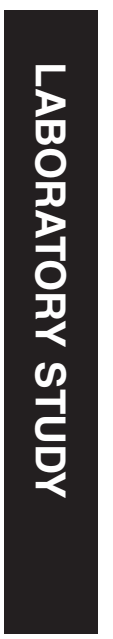

\title{
A hyaluronan hydrogel scaffold-based xeno-free culture system for ex vivo expansion of human corneal epithelial stem cells
}

${ }^{1}$ Eye Hospital, School of Optometry and

Ophthalmology, Wenzhou Medical University,

Wenzhou, China

${ }^{2}$ Ocular Surface Center, Cullen Eye Institute, Department of Ophthalmology, Baylor College of Medicine, Houston, TX, USA

${ }^{3}$ The Eye Institute, Xiamen University, Xiamen, China

Correspondence:

D-Q Li, Ocular Surface

Center, Cullen Eye Institute, Department of

Ophthalmology, Baylor

College of Medicine, 6565

Fannin Street, NC-505,

Houston, TX 77030, USA

Tel: +1713798 1123;

Fax: +1713 7981457

E-mail: dequan|@bcm.com

${ }^{4}$ These authors contributed equally to this work.

Received: 26 July 2016 Accepted in revised form: 9 December 2016

Published online:

17 February 2017

\begin{abstract}
Purpose To develop a hyaluronan hydrogel scaffold-based xeno-free culture system for ex vivo cultivation of human corneal epithelial stem cells (CESCs).

Patients and Methods CESCs were cultivated from donor limbal explants on the HyStem-C Hydrogel bio-scaffold in 12-well plates for 3 weeks. Group A used the traditional supplemented hormonal epidermal medium (SHEM) and group B used the defined SHEM (without fetal bovine serum and toxin A, adding $20 \%$ serum replacement). The growth and morphology of the cultured cells were assessed by phase contrast microscope. The expressions of specific cell markers were assessed by immunofluorescence staining and quantitative real-time PCR (qRT-PCR).

Results Successful cultures of CESCs were obtained in both groups, resulting in multilayered stratified epithelia. Comparing to group A, the cells in group B was grown slightly slower and formed less cellular layers at the end of culture. The corneal specific cytokeratin (K) 12 and differentiation markers, involucrin, and connexin 43 , were mainly expressed in the superficial cellular layers in both groups. Interestingly, certain basal cells were immune-positive to proposed stem cell markers such as K19, ABCG2, and integrin $\beta 1$ in both groups. There was no significant difference between the two groups with regard to the gene expression levels of all these selected corneal markers (all $P>0.05$ ). Conclusions The hyaluronan hydrogel scaffold-based xeno-free culture system may support the expansion of regenerative CESCs without the risk of xeno component
\end{abstract}

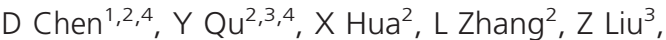
SC Pflugfelder ${ }^{2}$ and D-Q Li ${ }^{2}$ contamination. The regenerated epithelium maintains similar characteristics of native corneal epithelium.

Eye (2017) 31, 962-971; doi:10.1038/eye.2017.8; published online 17 February 2017

\section{Introduction}

The human corneal epithelium is a nonkeratinized stratified squamous epithelium, which is responsible for maintaining ocular surface health and is essential for good vision. The homeostasis and regeneration of corneal epithelia is maintained by the corneal epithelial stem cells (CESCs; also referred to as limbal stem cells). ${ }^{1,2}$ Ocular surface diseases with limbal stem cell deficiency, such as Stevens-Johnson syndrome, chemical, thermal and radiation injuries, extensive microbial infection, and inherited disorders are sight threatening and often cause blindness. ${ }^{3-6}$ Transplantation of limbal autograft or allograft is one of the most used methods to treat the limbal stem cell deficiency. ${ }^{7,8}$ Although corneal transplantation has achieved clinical success, there is an increasing shortage of corneal donors worldwide. There are over 10 million global blinding patients caused by corneal disease because of the lack of cornea donors for corneal transplantation. Corneal tissue engineering is becoming an important discipline that holds great promise for corneal transplantation to treat the blinding corneal diseases. ${ }^{9,10}$

Since the first clinical success of the cultivated corneal epithelial transplantation reported by Pellegrini, ${ }^{11}$ different methods have been 
developed to ex vivo cultivate corneal epithelium. ${ }^{12-14}$ However, these techniques have some limitations. One problem is that most culture methods are based on the use of allogenic or heterogenic biological products, such as human amniotic membrane, murine feeder cells, fetal bovine serum (FBS), and so on. These products carry the risk of transmitted diseases, tumorigenesis, or precipitation of immunologic rejection, as well as biologic variability. ${ }^{15}$ In addition, the isolation and purification of the cultivated corneal epithelial cells from the feeder layers such as the 3T3 feeder layers is challenging. ${ }^{15,16}$ So for the safety and ease of utilizing ex vivo cultivated CESCs, it is necessary to develop a new culture system with new carrier and xeno-free culture medium.

HyStem-C hydrogel is a commercial available substrate which can provide a three dimensional (3D) bio-scaffolds for cell culture. It has been reported to support several kinds of stem cells expansion ex vivo including human embryonic stem cells, human mesenchymal stem cells, hepatic progenitor cells, cardiac progenitor cells, and so on. ${ }^{17-20}$ In addition, its thiol-modified hyaluronan (HA) denatured collagen has been reported to stimulate the migration, adhesion, and proliferation of the corneal epithelium in wound model. ${ }^{21,22}$ However, to the best of our knowledge, there is no report regarding the utilization of this type of 3D bio-scaffolds for the ex vivo culture of CESCs.

In this study, we developed a HA hydrogel scaffolds based xeno-free culture system for ex vivo cultivation of CESCs. Considering the drawbacks of the xenobiotic components in the culture media, a defined supplement hormonal epithelial medium (SHEM) was used in the new culture system. The traditional FBS was replaced with KnockOut Serum Replacement (KnockOut SR, Thermo Fisher Scientific, Waltham, MA, USA). The phenotype and characteristics of the corneal epithelium regenerated from the CESCs were evaluated to assess the effect of the new culture system.

\section{Materials and methods}

\section{Reagents and materials}

HyStem-C Hydrogel kit was obtained as a gift from Biotime Inc. (Alameda, CA, USA). Dulbecco modified Eagle's medium (DMEM), Ham F12, amphotericin B, and gentamicin were from Invitrogen Corp. (Carlsbad, CA, USA). FBS was from Hyclone (Logan, UT, USA). Human insulin, transferrin, sodium selenite, hydrocortisone, epidermal growth factor (EGF), and cholera toxin subunit were from Sigma-Aldrich (St Louis, MO, USA). Cell culture dishes, plates, centrifuge tubes, and other plastic ware were purchased from Becton Dickinson and Company (Franklin Lake, NJ, USA). Nunc Lab-Tec II eight-chamber slides were from Nalge Nunc International Corp. (Naperville, IL, USA). Antibodies used in immunofluorescence staining were from Invitrogen Corp. (Carlsbad, CA, USA). Fresh human corneoscleral tissues were obtained from the Lions Eye Bank of Texas (LEBT, Houston, TX, USA). These tissues were stored in OptisolGS (Bausch and Lomb Inc., Rochester, NY, USA) at $4{ }^{\circ} \mathrm{C}$ until processed for culture. The details of the donors' conditions, tissue procurement, and length of preservation were given by the eye bank. The all tissues acquired and utilized from the Lions Eye Bank conform to the regulations relating to the use of Deceased Donor human tissue for research.

\section{Preparation of HyStem-C Hydrogel}

HyStem-C Hydrogel kit contains three main components: HyStem, Gelin-S, and Extralink. DG water is also supplied in the kit. The preparation of the normal hydrogel was according to the protocol of the kit. In brief, HyStem, Gelin-S, and Extralink were totally dissolved by DG water, with the assistance of calefaction at $37^{\circ} \mathrm{C}$ and vortex. Equal volumes of HyStem and Gelin-S well were mixed by pipetting. Extralink was then added to the HyStem and Gelin-S mixture (1:2 volume ratio) as recommended in the protocol. The mixture was used to coat the inserts placed in 12-well plate within $30 \mathrm{~min}$ at room temperature before the gelation formed.

\section{Culture of corneal epithelial cells on HyStem-C Hydrogel in SHEM medium vs defined SHEM medium}

Human corneal epithelial cells were cultured using explants from limbal rims by our previous method. ${ }^{23,24}$ In brief, each limbal rim was trimmed and dissected into $\sim 2 \mathrm{~mm} \times 2 \mathrm{~mm}$ sized explants. Each piece was placed onto the culture insert with HyStem-C Hydrogel coated in 12-well plates. Two culture media were used. Group A used traditional SHEM, consisting of a 1:1 mixture of DMEM and Ham's F12 medium containing $5 \mathrm{ng} / \mathrm{ml}$ EGF, $5 \mu \mathrm{g} / \mathrm{ml}$ insulin, $5 \mu \mathrm{g} / \mathrm{ml}$ transferrin, $5 \mathrm{ng} / \mathrm{ml}$ sodium selenite, $0.5 \mu \mathrm{g} / \mathrm{ml}$ hydrocortisone, $30 \mathrm{ng} / \mathrm{ml}$ toxin $\mathrm{A}$, $0.5 \%$ DMSO, $50 \mu \mathrm{g} / \mathrm{ml}$ gentamicin, $1.25 \mu \mathrm{g} / \mathrm{ml}$ amphotericin B, and 5\% FBS. Group B used defined SHEM, consisting of $20 \%$ serum replacement (Knockout SR, Thermo Fisher Scientific) and all the other components of traditional SHEM except FBS and toxin A (Figure 1). The cells were cultured under $5 \% \mathrm{CO}_{2}$ at $37^{\circ} \mathrm{C}$ and $95 \%$ humidity for 21 days. The medium was renewed every 2-3 days. 


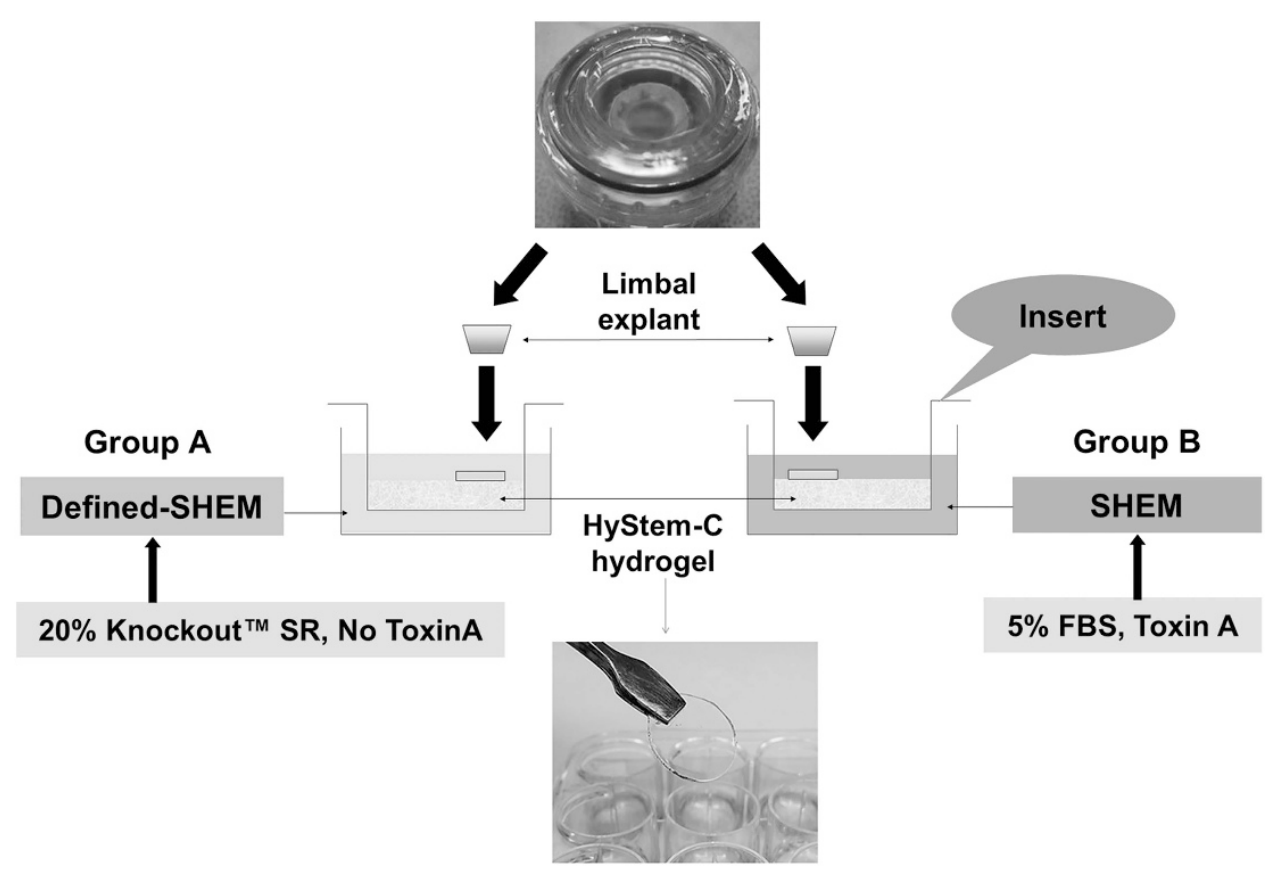

Figure 1 Ex vivo cultivation of human CESCs in a HA hydrogel scaffold-based culture system. Fresh limbal explant was trimmed and dissected into $\sim 2 \mathrm{~mm} \times 2 \mathrm{~mm}$ sized pieces and placed onto the HyStem-C Hydrogel-coated culture inserts in 12-well plates. Two culture media were used. Group A used traditional SHEM including toxin A and 5\% FBS. Group B used defined SHEM without toxin A and 5\% FBS, but included 20\% serum replacement (Knockout SR, Thermo Fisher Scientific). The HyStem-C Hydrogel has a good stiffness and can be manipulated with forceps.

\section{Hematoxylin and eosin staining}

Corneal epithelial cells cultured on HyStem-C Hydrogel were fixed in $4 \%$ paraformaldehyde for $30 \mathrm{~min}$ at $4{ }^{\circ} \mathrm{C}$, and then embedded in OCT Compound (SAKURA, Tissue-Tek, Torrance, CA, USA), stored at $-80^{\circ} \mathrm{C}$. Cryosections of $6 \mu \mathrm{m}$ thickness were fixed in acetone at $-20^{\circ} \mathrm{C}$ for $10 \mathrm{~min}$. Subsequently, hematoxylin and eosin (H\&E; Sangon biotech, Shanghai, China) staining were performed and observed under a light microscope with a digital camera (Nikon Eclipse 50i, Tokyo, Japan).

\section{Immunofluorescent staining}

The phenotype and characteristics of the regenerated cells on HyStem-C Hydrogels were evaluated by immunofluorescence staining for their expression of differentiation markers (K12, Involucrin, and Connexin 43 ) and proposed stem cell markers (K19, Integrin $\beta 1$, and ABCG2). Immunofluorescent staining was performed on cryosections from tissues and cultivated constructs using a previously reported method. ${ }^{24,25}$ In brief, the sample slides were fixed in cold methanol, permeabilized with $0.2 \%$ Triton X-100 in PBS for 15 min and blocked with $10 \%$ donkey serum for 1 hour at room temperature. Then they were incubated with primary antibodies against, K12 (1: 50), Involucrin $(1: 50)$, Connexin 43 (1:100), K19 $(1: 100)$, integrin $\beta 1(1: 50)$, and ABCG2 $(1: 100)$ at $4{ }^{\circ} \mathrm{C}$ overnight. Using the Alexa Fluor 488 conjugated secondary antibodies (Thermo Fisher Scientific, Waltham, MA, USA) to incubate in a dark chamber for $1 \mathrm{~h}$ at room temperature. Counter-stain nucleus with propidium iodide (PI, Sigma-Aldrich, West Chester, PA, USA). Sections were examined and photographed with an epifluorescent microscope (Eclipse 400, Nikon, Tokyo, Japan) with a digital camera (DMX 1200, Nikon).

\section{RNA extraction, reverse transcription, and quantitative real-time PCR}

Total RNA was extracted with RNeasy Plus Mini Kit (Qiagen, Valencia, CA, USA) according to the manufacturer's instructions, quantified with a spectrophotometer (NanoDrop ND-1000; Thermo Scientific, Wilmington, DE, USA), and stored at $-80^{\circ} \mathrm{C}$ before use. The first strand cDNA was synthesized by RT from $2 \mu \mathrm{g}$ of total RNA using Ready-To-Go You-Prime First-Strand Beads as previously described. ${ }^{26}$ Quantitative real-time PCR (qRT-PCR) was performed in StepOnePlus Real-Time PCR System (Applied Biosystems, Foster City, CA, USA) with $10 \mu \mathrm{l}$ reaction volume containing $4 \mu \mathrm{l}$ of cDNA, $0.3 \mu \mathrm{l}$ TaqMan gene expression assay, $5 \mu \mathrm{l}$ TaqMan gene expression master mix and $0.7 \mu 1 \mathrm{H}_{2} \mathrm{O}$. TaqMan gene expression assays used for this study were listed in Supplementary Table 1 . The thermocycler parameters 
were $50^{\circ} \mathrm{C}$ for $2 \mathrm{~min}$ and $95^{\circ} \mathrm{C}$ for $10 \mathrm{~min}$, followed by 40 cycles of $95^{\circ} \mathrm{C}$ for $15 \mathrm{~s}$, and $60{ }^{\circ} \mathrm{C}$ for $1 \mathrm{~min}$. A nontemplate control was included to evaluate DNA contamination. The results were analyzed by the comparative threshold cycle $(\mathrm{Ct})$ method and normalized by GAPDH as an internal control. Twelve cultures from each group were collected for qRT-PCR and data analysis (Sample size $(n)=12$ ).

\section{Statistical analysis}

Statistical analyses were performed using statistical software (SPSS for Windows, V.16.0 SPSS Science, Chicago, IL, USA). The data was presented as the mean value $\pm S D$. Group means were compared using the independent samples $t$-test. Test results are two-sided, where $P<0.05$ is considered statistically significant.

\section{Results}

Cultivation of corneal epithelium on HyStem-C Hydrogel from limbal epithelium where stem cells reside

A total 20 of corneoscleral tissues were obtained from donors with an average age of $57.57 \pm 9.36$ years (range: 47-70 years). These tissues were collected and preserved within $24 \mathrm{~h}$ after death. The time from death to culture was $4.2 \pm 1.4$ days (range: $3-7$ days). Cultured epithelial cells were assessed under the phase contrast microscopy (Figure 2). The outgrowths of limbal epithelial cells were emerged around 3-4 days in group A, and around 4-5 days in group $B$. The regenerated cells in both groups exhibited a cobblestone like morphology with a variable size, shape, and nuclei/cytoplasm ratio, which were similar to the cellular morphology of normal corneal epithelial cells at the early cultivated stage. However, some cells of fusiform fibroblast-like cells were emerged later in group B. The cultivated epithelial cells covered the whole Hydrogel-coated inserts around 14-15 days in group A, and around 18-20 days in group B.

\section{Histological comparison of the corneal epithelia cultured on HyStem-C Hydrogels in different media}

The histology of the tissue generated on HyStem-C Hydrogel scaffolds in the two groups was compared by cross-section with HE staining. At the early stage of cultivation around 1 week, a single layer of cells covering the scaffold surface was observed in both groups. At the end of cultivation, the cultured cells formed a $3 \mathrm{D}$ stratified cell sheet of 5-7 cellular layers in group A, whereas less cellular layers (3-5 layers) were observed in group B (Figure 3). Cells in the basal layer were polygonal, and became more flattened in the suprabasal and superficial layers in both groups, which resembles the native-like human corneal epithelial morphology and structure in vivo. In contrast, the cellular layers of the artificial epithelium cultured in defined SHEM seemed less organized and striated than those cultured in SHEM. These results indicate that the HyStem-C Hydrogels may offer substrate similar to corneal stroma to cultivate a native-like corneal epithelium.
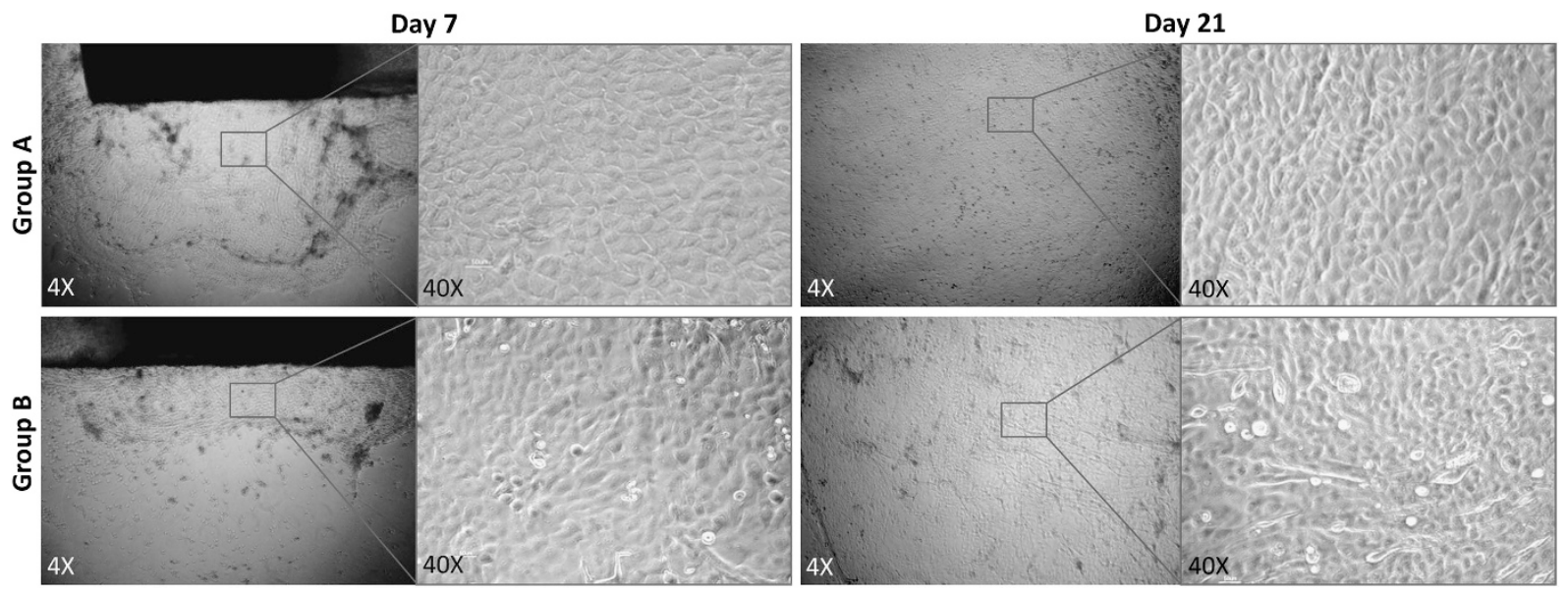

Figure 2 Demonstration of growth of limbal epithelial cells as observed under phase contrast microscope. The corneal epithelial cells were proliferating from the periphery of the explant onto the HyStem-C Hydrogel scaffolds within 7 days in both groups. The cells in group A appeared to grow faster than those in group B. The cultivated epithelial cells covered the whole hydrogel-coated insert at the end of culture at day 21. The regenerated cells in both media exhibited a cobblestone like morphology, whereas some cells showed fusiform in group B. Magnification: left, $\times 4$; right, $\times 40$. 
Day 7

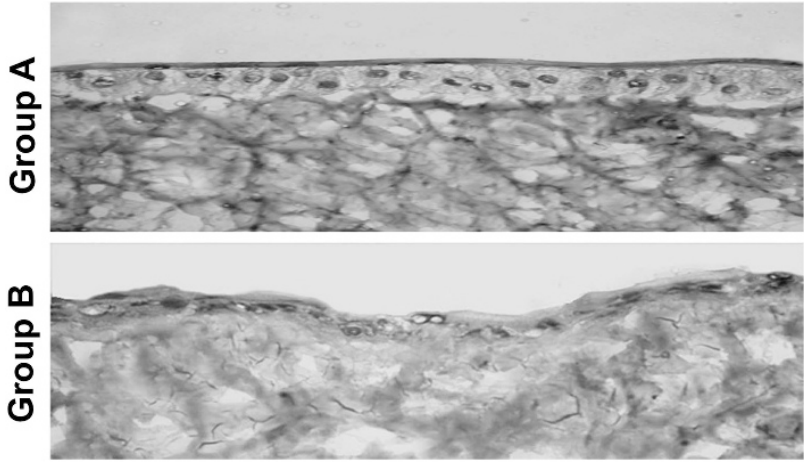

Day 21

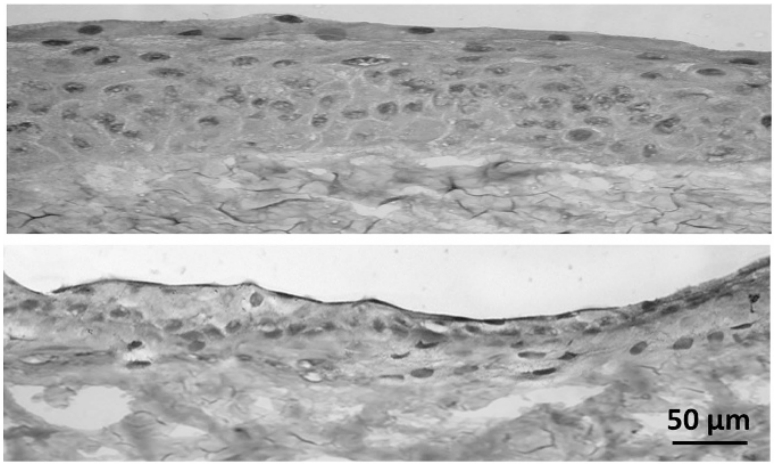

Figure 3 The histology of the tissue generated on hydrogel scaffolds by cross-section with HE staining. At the early stage of cultivation around 1 week, a single cell layer cover the scaffold surface was observed in both media. At the end of cultivation, the cultured cells formed an artificial epithelium of 5-7 cellular layers in group A, whereas less cellular layers (3-5 layers) were observed in group B. The cellular layer(s) cultured in group B seemed less organized and striated than those cultured in group A.

Immunostaining of specific corneal epithelial cell markers and stem cell-associated markers in regenerated cells on HyStem-C Hydrogels in different media

Expression of differentiation markers $\mathrm{K} 12$ is a keratin expressed in corneal epithelia and well known as a specific epithelial cell marker. ${ }^{27}$ The cytoplasmic expression of K12 was detected in the whole cellular layers in the artificial corneal epithelium cultivated on hydrogel in both groups. Involucrin is found in the cytosol of differentiated human keratinocytes. ${ }^{28}$ The expression of involucrin was mainly located in the superficial and middle-upper layers in group A, and was mainly located in the superficial layer in group B. CX43 is a member of the gap junction protein family involving in the gap junction between the epithelial cells and serves as another differentiation marker. ${ }^{29}$ CX43 was positively expressed in the superficial and middle-upper layers of the artificial epithelia regenerated in both groups (Figure 4).

Expression of stem cell-associated markers The stemness of the cells grown from the limbal explants was verified with the proposed epithelial stem/progenitor cell markers. Keratin 19 (K19), an intermediate filament protein in epidermal follicle progenitors and a putative stem cell marker, is expressed in the basal and peripheral regions of the limbus in vivo. ${ }^{30}$ In this study, we observed that K19 was expressed in all cellular layers of the artificial corneal epithelium regenerated in both groups. Integrin $\beta 1$ was previously proposed as putative stem cell markers for epidermal keratinocytes. ${ }^{25}$ Integrin $\beta 1$ antibody was strongly stained in the basal and superbasal cellular layers of the tissue regenerated in both groups. ABCG2, a member of the ATP-binding cassette (ABC) transporters, has been proposed as a universal marker for stem cell. ${ }^{31}$ ABCG2 expression was mainly detected in the basal layer of the artificial epithelia cultivated in both groups in our study (Figure 4).

\section{Gene expression of molecular markers in regenerated corneal epithelium on HyStem-C Hydrogels in different media}

With the house keeping gene, GAPDH, as an internal control, RT-qPCR disclosed an expression of corneal epithelial cell differentiation markers and stem cellassociated markers in the cultured tissues and compared between the two groups. There was no significant difference in mRNA levels of all these markers between the two groups (all $P>0.05$; Supplementary Table 2; Figure 5).

\section{Discussion}

To date, there are a variety of different methods for ex vivo cultivating CESCs. Among these methods, substrate is one of the key factors in corneal tissue engineering. There are several considerations to take into account when choosing the appropriate substrate on which to expand and differentiate cells: optically transparent, supporting corneal epithelial progenitor cell survival, promoting cell differentiation to form a native-like stratified epithelium, and serving as a carrier for easy transplantation to patients. Many attempts have been made for using human amniotic membrane (HAM), ${ }^{32,33}$ anterior lens capsule, ${ }^{34}$ and other bio-scaffolds such as fibrin glue, ${ }^{35}$ fibrin gel, ${ }^{36}$ and temperature-responsive polymer. ${ }^{37}$ HAM appears to be the most preferable growth substrate and carrier for limbal stem cell culture due to its biodegradable and immunosuppressive properties during transplantation, although its thickness and variable transparency have been a counter argument for its use. In addition, most bio-scaffolds involve the co-culture of the 
limbal epithelium with a mitotically inactivated 3T3 mouse fibroblast feeder layer. ${ }^{38}$ The known potential risks of the murine 3T3 feeder layer include xenogenic microchimerism, xenoantigenicity, and disease transmission through contamination with viruses or prion agents. $^{39,40}$

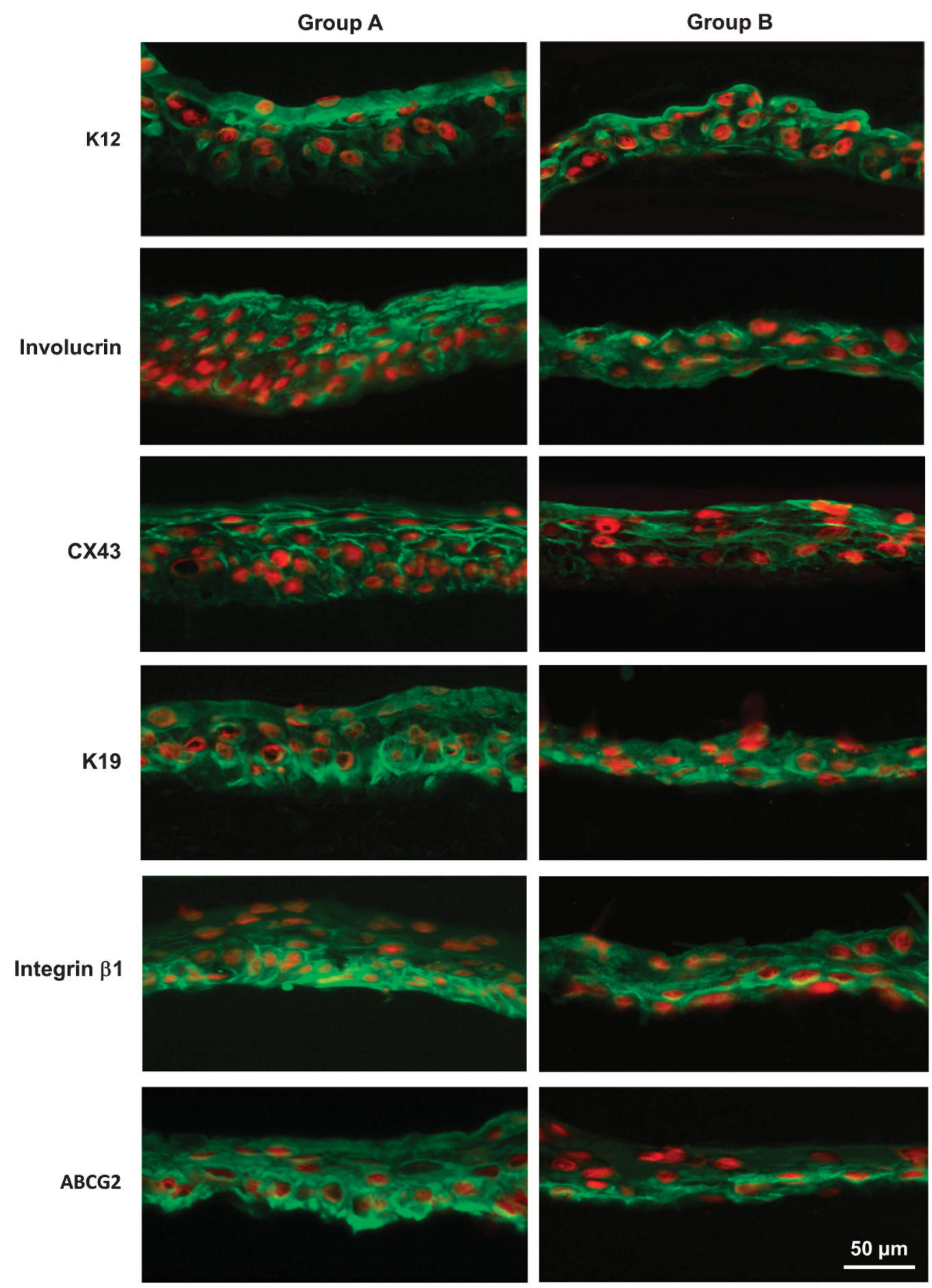

Figure 4 Immunofluorescent staining of differentiation markers and stem cell-associated markers of corneal epithelial cells cultivated on hydrogel scaffolds in different media. The cytoplasmic expression of K12 was detected in the superficial cellular layers in both groups. Involucrin was positively expressed in the superficial and middle-upper layers in group A, and was mainly expressed in the superficial layer in group B. CX43 was positively expressed in the superficial and middle-upper layers in both groups. K19, Integrin $\beta 1$ and ABCG2 were mainly expressed in the basal layer of the artificial corneal epithelium regenerated in both groups. 


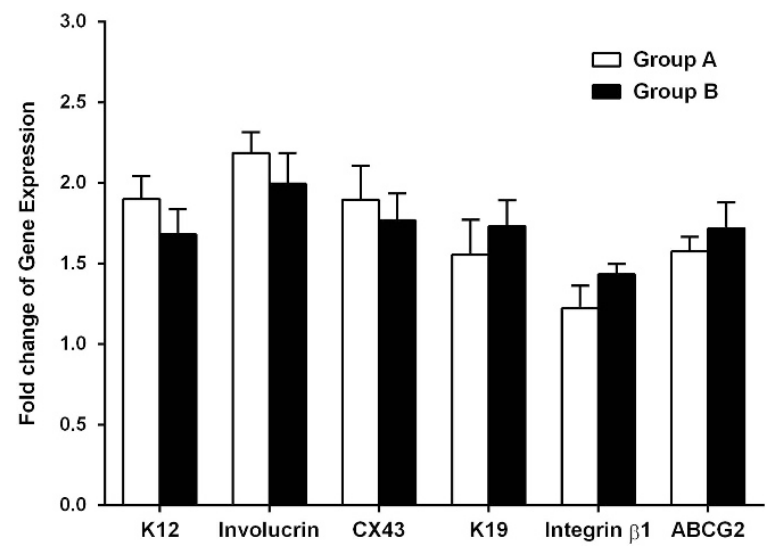

Figure 5 Gene expression of corneal epithelial cell differentiation markers and stem cell-associated markers in regenerated corneal epithelium on hydrogel scaffolds in different media. There was no significant difference in mRNA levels of all these markers between the two groups (all $P>0.05$ ).

HyStem-C hydrogel is a commercial available substrate that can provide an excellent starting point for optimizing the matrix for cell culture. HyStem-C is fully chemically-defined and based on three biocompatible components in the HyStem-C Hydrogel kit (ESI BIO, Alameda, CA, USA): thiol-modified HA (Glycosil), thiolreactive crosslinker, PEGDA (Extralink), and thiolmodified denatured collagen (Gelin-S). HA, also referred to as hyaluronic acid, is an ideal material for natural scaffolds in tissue engineering thanks to its unique properties of biocompatibility, chemical functionalization and degradability. ${ }^{41-43}$ HA hydrogel has been reported to support the ex vivo expansion of several types of stem cells such as human embryonic stem cells, human mesenchymal stem cells, hepatic progenitor cells, and cardiac progenitor cells. ${ }^{17-20} \mathrm{HA}$-based biomaterials have also been used in various corneal cell culture such as corneal keratocytes and endothelial cells. ${ }^{44,45}$ Gelin-S has been reported to provides basic cell-attachment sites for a wide variety of primary cells and stem cells expansion ex vivo, ${ }^{17-20}$ and stimulate the migration, adhesion, and proliferation of the corneal epithelium in wound model. ${ }^{21,22}$ In this study, HyStem-C hydrogel on the inserts were used to culture fresh human limbal explants. We proposed that HyStem-C hydrogel may provide a unique microenvironment for the self-renewal and differentiation of CESCs. This hydrogels can be easily customized to possess the desired stiffness and gelation time by manipulating component concentration and mixing ratios. The stiffness of the gel was strengthened by adding two folds of cross-linking agent (Extralink) into the gel mixture as recommended by the manufacturer. The rationality lies in that the relative levels of epithelial cell differentiation has been reported to be influenced by the collagen substrate stiffness. ${ }^{46}$ The H\&E staining showed the well stratified and well organized native-like corneal epithelial structure cultured in SHEM medium, which is not often seen in corneal epithelia cultivated on other substrates such as $\mathrm{HAM}^{33}$ temperature-responsive culture surface. ${ }^{37}$ Our results showed that HyStem-C hydrogel could promote the growth and stratification of limbal epithelial cells.

Apart from optimal substrate, an optimal nutrient requirement is also important in corneal tissue engineering. Nowadays, most investigational protocols of different techniques for limbal epithelial cell cultivation considerably involved animal-derived components or xenobiotic products such as FBS and toxin A in the growth media. ${ }^{47,48}$ Similar to the aforementioned murine 3T3 feeder layer, the co-culture of human limbal stem cells with FBS and toxin A raises concern about infection with recognized or unknown agents, ${ }^{49}$ although the probability of potential harm in regard to the risk was very low. However, these consequences may be more likely in patients receiving allogeneic grafts combined with immunosuppression. Therefore, it would be preferable to ex vivo culture CESCs in xenobiotic material free medium for transplantation purposes. ${ }^{50}$ Autologous serum has been used instead of FBS in media to cultivate human CESCs. ${ }^{51}$ Nonetheless, the use of autologous serum may be contraindicated in particular patients such as those with significant cerebrovascular or cardiovascular disease, anemia, active bacterial or fungal infection, and positive viral serology. Serum-free media such as KSFM and Epilife has been reported to successfully cultivate corneal limbal explants on HAMs. ${ }^{50}$ However, the efficacy may not be as high as the traditional medium and cannot meet the need of high quantity corneal epithelia in short time and the drawbacks of using HAM still exist. In our study, we used the defined SHEM that obviated the use of the xenobiotic components such as 3T3 feeder cells, FBS, and toxin A. FBS was replaced by $20 \%$ serum replacement (Knockout SR, Thermo Fisher Scientific). KnockOut SR is a defined serum-free formulation, which was designed to directly replace FBS for maintenance of embryonic stem cells and induced pluripotent stem cells. ${ }^{52,53}$

The effect of the defined SHEM was compared with that of the traditional SHEM. The growth of corneal epithelial cells in the defined SHEM seemed to be slower compared with those cultured in SHEM medium in this study. The clusters of corneal epithelial cells were observed at the edge of the explant around 3-4 days and reached confluence, covering the entire Hydrogel scaffold within a period of 14-15 days in the SHEM. In contrast, the initial emerging and full growth time of the cultivated cells was $4-5$ days and 18-20 days, respectively. Nevertheless, the growth rate is comparable to the previous reported studies. ${ }^{50,54}$ Histologically, the corneal epithelial sheets regenerated at the end of cultivation were slightly thinner and less stratified in defined SHEM 
compared with those cultured in SHEM. The different components in these two media may account for the difference in cellular behaviors. ${ }^{50}$ In addition, uneven growth from limbal explants may also contribute to the difference of stratification due to that every piece of limbal explants contains different number of CESCs. Further investigation is necessary to improve the quality of corneal epithelial regeneration.

The phenotype and characteristics of the regenerated corneal epithelial cells on Hydrogels scaffolds in both media were further compared using immunofluorescence staining and gene expression of specific cell markers. K12 is well known as a specific corneal epithelial cell marker. ${ }^{27}$ The regenerated epithelium cultured in both SHEM and defined SHEM media showed positive expression of K12 in the whole cellular layers, suggesting that the regenerated cells from the limbal explants could keep the normal type of corneal epithelial cells. Features of differentiated corneal epithelial cells cultured both media were further confirmed by the significant expression of Involucrin and CX43, which are proven differentiated markers for corneal epithelial cells. ${ }^{25,29}$ The presence of these markers indicates that the engineered epithelium in the new culture system underwent normal differentiation which mimics this in vivo response by limbal epithelial cells. Interestingly, these regenerated cells not only showed a phenotype similar to the typical human corneal epithelium but also showed characteristic of stem cells to some extent, according to their sharing same expressed patterns of limbal stem cell markers with native human limbal epithelium. K19, a putative stem cell marker being expressed in the limbal epithelial cells in vivo, ${ }^{30}$ was positive expressed in the regenerated epithelium cultured in both SHEM and defined SHEM media. The stem/progenitor cell markers integrin $\beta 1$ and ABCG2 were also more strongly immunelocated in the basal layer than in suprabasal layer of the artificial corneal epithelium. The high expression of integrin $\beta 1$ indicates the strong adhesion of the cultured basal cells to specific extracellular matrix ligands. ${ }^{25}$ ABCG2 is proposed as a universal marker for stem cell, which is primarily immune-detected in the cell membrane and cytoplasm of certain limbal basal epithelial cells. ${ }^{31,55}$ These findings demonstrate that the regenerated corneal epithelium shares some phenotype of limbal stem cells, suggesting it contains more stem/progenitor cells, an important feature for maintaining proliferation capacity and self-renewal. There was no significant difference in gene expression level of all these markers between the two groups. This indicates that the phenotype and characteristics of the cultivated cells may not be affected by the modification of the culture media.

Although the artificial epithelia cultured on hydrogel scaffolds in defined SHEM seemed slightly less organized in morphology and histology comparing to those in
SHEM, they still showed typical phenotype and characteristics of the corneal epithelial cells and maintain stemness and proliferative potential to some extent. These data demonstrate that the xeno-free culture system can sufficiently support the expansion of CESCs, although the cell growth did not seem to be better than the traditional culture system. However, the outcome is promising considering that the xenobiotic components were eliminated and the risk of potential disease transmission was lowered. Given safety and feasibility considerations, this technique may offer a reasonable way to expand corneal epithelium in culture for tissue engineering.

Nevertheless, the formula of xeno-free culture medium also needs to be modified to cultivate and obtain transplantable corneal tissue for clinical use. Further improvement in the HyStem-C hydrogel based bio-scaffold substrate is needed to form a $3 \mathrm{D}$ microstructure mimicking the limbal niches where the CESCs reside. Comparison of the difference between $3 \mathrm{D}$ vs $2 \mathrm{D}$ to reflect the significant role of using 3D HA hydrogel structure to control specific cell behaviors would be more interesting and needs to be included in our future plan. In addition, this work did not include the experimental groups of CESCs cultured in absence of HyStem-C. Further studies are necessary to investigate the advantages and underlying mechanism of HyStem-C hydrogel carrier in maintaining CESC stemness.

In conclusion, our study demonstrates that human corneal epithelium can be regenerated using the HA hydrogel scaffold-based xeno-free culture system. A native-like corneal equivalent construct with proliferative potential can be bioengineered with this new culture system. With future improvement, the cultivated corneal epithelia may be applied to clinical transplantation in the treatment of limbal stem cell deficiency-related diseases.

\section{Summary}

\section{What was known before}

- Traditional culture methods are based on the use of allogenic or heterogenic biological products, such as HAM, murine feeder cells, FBS, and so on, which carry the risk of transmitted diseases, tumorigenesis, or precipitation of immunologic rejection, as well as biologic variability.

What this study adds

- We developed a HA hydrogel scaffold-based xeno-free culture system, which can support the expansion of regenerated CESCs without the risk of xeno component contamination.

\section{Conflict of interest}

The authors declare no conflict of interest. 


\section{Acknowledgements}

We thank the Lions Eye Bank of Texas for their great support in providing human corneoscleral tissues. This study was supported by National Institutes of Health grant EY023598 (DQL), Core grant for Vision Research EY002520, Lions Foundation for Sight, Research to Prevent Blindness, Oshman Foundation, and William Stamps Farish Fund.

\section{References}

1 Cotsarelis G, Cheng SZ, Dong G, Sun TT, Lavker RM. Existence of slow-cycling limbal epithelial basal cells that can be preferentially stimulated to proliferate: implications on epithelial stem cells. Cell 1989; 57: 201-209.

2 Thoft RA, Friend J. The X, Y, Z hypothesis of corneal epithelial maintenance. Invest Ophthalmol Vis Sci 1983; 24: 1442-1443.

3 Dua HS. Stem cells of the ocular surface: scientific principles and clinical applications. Br J Ophthalmol 1995; 79: 968-969.

4 Pfister RR. Corneal stem cell disease: concepts, categorization, and treatment by auto- and homotransplantation of limbal stem cells. CLAO J 1994; 20: 64-72.

5 Tseng SC. Concept and application of limbal stem cells. Eye 1989; 3(Pt 2): 141-157.

6 Dua HS, Saini JS, Azuara-Blanco A, Gupta P. Limbal stem cell deficiency: concept, aetiology, clinical presentation, diagnosis and management. Indian J Ophthalmol 2000; 48: 83-92.

7 Rama P, Matuska S, Paganoni G, Spinelli A, De Luca M, Pellegrini G. Limbal stem-cell therapy and long-term corneal regeneration. N Engl J Med 2010; 363: 147-155.

8 Shortt AJ, Secker GA, Rajan MS, Meligonis G, Dart JK, Tuft SJ et al. Ex vivo expansion and transplantation of limbal epithelial stem cells. Ophthalmology 2008; 115: 1989-1997.

9 Germain L, Carrier P, Auger FA, Salesse C, Guerin SL. Can we produce a human corneal equivalent by tissue engineering? Prog Retin Eye Res 2000; 19: 497-527.

10 Selvam S, Thomas PB, Yiu SC. Tissue engineering: current and future approaches to ocular surface reconstruction. Ocul Surf 2006; 4: 120-136.

11 Pellegrini G, Traverso CE, Franzi AT, Zingirian M, Cancedda R, De Luca M. Long-term restoration of damaged corneal surfaces with autologous cultivated corneal epithelium. Lancet 1997; 349: 990-993.

12 Koizumi N, Inatomi T, Suzuki T, Sotozono C, Kinoshita S. Cultivated corneal epithelial stem cell transplantation in ocular surface disorders. Ophthalmology 2001; 108: 1569-1574.

13 Rama P, Bonini S, Lambiase A, Golisano O, Paterna P, De Luca $\mathrm{M}$ et al. Autologous fibrin-cultured limbal stem cells permanently restore the corneal surface of patients with total limbal stem cell deficiency. Transplantation 2001; 72: 1478-1485.

14 Doillon CJ, Watsky MA, Hakim M, Wang J, Munger R, Laycock $\mathrm{N}$ et al. A collagen-based scaffold for a tissue engineered human cornea: physical and physiological properties. Int J Artif Organs 2003; 26: 764-773.
15 Tseng SC, Chen SY, Shen YC, Chen WL, Hu FR. Critical appraisal of ex vivo expansion of human limbal epithelial stem cells. Curr Mol Med 2010; 10: 841-850.

16 Lu R, Bian F, Lin J, Su Z, Qu Y, Pflugfelder SC et al. Identification of human fibroblast cell lines as a feeder layer for human corneal epithelial regeneration. PLoS One 2012; 7: e38825.

17 Liu Y, Charles LF, Zarembinski TI, Johnson KI, Atzet SK, Wesselschmidt RL et al. Modified hyaluronan hydrogels support the maintenance of mouse embryonic stem cells and human induced pluripotent stem cells. Macromol Biosci 2012; 12: 1034-1042.

18 Lindborg BA, Brekke JH, Scott CM, Chai YW, Ulrich C, Sandquist L et al. A chitosan-hyaluronan-based hydrogelhydrocolloid supports in vitro culture and differentiation of human mesenchymal stem/stromal cells. Tissue Eng Part A 2015; 21: 1952-1962.

19 Deegan DB, Zimmerman C, Skardal A, Atala A, Shupe TD. Stiffness of hyaluronic acid gels containing liver extracellular matrix supports human hepatocyte function and alters cell morphology. J Mech Behav Biomed Mater 2015; 55: 87-103.

20 Gaetani R, Feyen DA, Verhage V, Slaats R, Messina E, Christman KL et al. Epicardial application of cardiac progenitor cells in a 3D-printed gelatin/hyaluronic acid patch preserves cardiac function after myocardial infarction. Biomaterials 2015; 61: 339-348.

21 Gomes JA, Amankwah R, Powell-Richards A, Dua HS. Sodium hyaluronate (hyaluronic acid) promotes migration of human corneal epithelial cells in vitro. Br J Ophthalmol 2004; 88: 821-825.

22 Nishida T, Nakamura M, Mishima H, Otori T. Hyaluronan stimulates corneal epithelial migration. Exp Eye Res 1991; 53: 753-758.

23 Chen Z, Li DQ, Tong L, Stewart P, Chu C, Pflugfelder SC. Targeted inhibition of p57 and p15 blocks transforming growth factor beta-inhibited proliferation of primary cultured human limbal epithelial cells. Mol Vis 2006; 12: 983-994.

24 Kim HS, Jun Song X, de Paiva CS, Chen Z, Pflugfelder SC, Li DQ. Phenotypic characterization of human corneal epithelial cells expanded ex vivo from limbal explant and single cell cultures. Exp Eye Res 2004; 79: 41-49.

25 Chen Z, de Paiva CS, Luo L, Kretzer FL, Pflugfelder SC, Li DQ. Characterization of putative stem cell phenotype in human limbal epithelia. Stem Cells 2004; 22: 355-366.

26 Yoon KC, De Paiva CS, Qi H, Chen Z, Farley WJ, Li DQ et al. Expression of Th- 1 chemokines and chemokine receptors on the ocular surface of C57BL/6 mice: effects of desiccating stress. Invest Ophthalmol Vis Sci 2007; 48: 2561-2569.

27 Kurpakus MA, Maniaci MT, Esco M. Expression of keratins K12, K4 and K14 during development of ocular surface epithelium. Curr Eye Res 1994; 13: 805-814.

28 Banks-Schlegel S, Green H. Involucrin synthesis and tissue assembly by keratinocytes in natural and cultured human epithelia. J Cell Biol 1981; 90: 732-737.

29 Chen Z, Evans WH, Pflugfelder SC, Li DQ. Gap junction protein connexin 43 serves as a negative marker for a stem cell-containing population of human limbal epithelial cells. Stem Cells 2006; 24: 1265-1273.

30 Michel M, Torok N, Godbout MJ, Lussier M, Gaudreau P, Royal A et al. Keratin 19 as a biochemical marker of skin stem cells in vivo and in vitro: keratin 19 expressing cells are differentially localized in function of anatomic sites, and 
their number varies with donor age and culture stage. J Cell Sci 1996; 109(Pt 5): 1017-1028.

31 Zhou S, Schuetz JD, Bunting KD, Colapietro AM, Sampath J, Morris JJ et al. The ABC transporter Bcrp1/ABCG2 is expressed in a wide variety of stem cells and is a molecular determinant of the side-population phenotype. Nat Med 2001; 7: 1028-1034.

32 Meller D, Pires RT, Tseng SC. Ex vivo preservation and expansion of human limbal epithelial stem cells on amniotic membrane cultures. Br J Ophthalmol 2002; 86: 463-471.

33 Koizumi N, Fullwood NJ, Bairaktaris G, Inatomi T, Kinoshita S, Quantock AJ. Cultivation of corneal epithelial cells on intact and denuded human amniotic membrane. Invest Ophthalmol Vis Sci 2000; 41: 2506-2513.

34 Galal A, Perez-Santonja JJ, Rodriguez-Prats JL, Abad M, Alio J. Human anterior lens capsule as a biologic substrate for the ex vivo expansion of limbal stem cells in ocular surface reconstruction. Cornea 2007; 26: 473-478.

35 Sharma S, Tandon R, Mohanty S, Sharma N, M V, Sen S et al. Culture of corneal limbal epithelial stem cells: experience from benchtop to bedside in a tertiary care hospital in India. Cornea 2011; 30: 1223-1232.

36 Varga N, Vereb Z, Rajnavolgyi E, Nemet K, Uher F, Sarkadi B et al. Mesenchymal stem cell like (MSCl) cells generated from human embryonic stem cells support pluripotent cell growth. Biochem Biophys Res Commun 2011; 414: 474-480.

37 Wearne KA, Winter HC, Goldstein IJ. Temporal changes in the carbohydrates expressed on BG01 human embryonic stem cells during differentiation as embryoid bodies. Glycoconj J 2008; 25: 121-136.

38 Cristovam PC, Gloria MA, Melo GB, Gomes JA. Importance of 3T3 feeder layer to establish epithelial cultures from cell suspension obtained from corneo-scleral rims. Arq Bras Oftalmol 2008; 71: 689-694.

39 Boneva RS, Folks TM, Chapman LE. Infectious disease issues in xenotransplantation. Clin Microbiol Rev 2001; 14: 1-14.

40 Hultman CS, Brinson GM, Siltharm S, deSerres S, Cairns BA, Peterson HD et al. Allogeneic fibroblasts used to grow cultured epidermal autografts persist in vivo and sensitize the graft recipient for accelerated second-set rejection. J Trauma 1996; 41: 51-58.

41 Highley CB, Prestwich GD, Burdick JA. Recent advances in hyaluronic acid hydrogels for biomedical applications. Curr Opin Biotechnol 2016; 40: 35-40.

42 Burdick JA, Prestwich GD. Hyaluronic acid hydrogels for biomedical applications. Adv Mater 2011; 23: H41-H56.

43 Hemshekhar M, Thushara RM, Chandranayaka S, Sherman LS, Kemparaju K, Girish KS. Emerging roles of hyaluronic acid bioscaffolds in tissue engineering and regenerative medicine. Int J Biol Macromol 2016; 86: 917-928.

44 Lai JY, Cheng HY, Ma DH. Investigation of overrunprocessed porous hyaluronic acid carriers in corneal endothelial tissue engineering. PLoS One 2015; 10: e0136067.

45 Lai JY, Tu IH. Adhesion, phenotypic expression, and biosynthetic capacity of corneal keratocytes on surfaces coated with hyaluronic acid of different molecular weights. Acta Biomater 2012; 8: 1068-1079.

46 Jones RR, Hamley IW, Connon CJ. Ex vivo expansion of limbal stem cells is affected by substrate properties. Stem Cell Res 2012; 8: 403-409.

47 Baylis O, Figueiredo F, Henein C, Lako M, Ahmad S. 13 years of cultured limbal epithelial cell therapy: a review of the outcomes. J Cell Biochem 2011; 112: 993-1002.

48 Shortt AJ, Secker GA, Notara MD, Limb GA, Khaw PT, Tuft SJ et al. Transplantation of ex vivo cultured limbal epithelial stem cells: a review of techniques and clinical results. Surv Ophthalmol 2007; 52: 483-502.

49 Tekkatte C, Gunasingh GP, Cherian KM, Sankaranarayanan K. 'Humanized' stem cell culture techniques: the animal serum controversy. Stem Cells Int 2011; 2011: 504723.

50 Lekhanont K, Choubtum L, Chuck RS, Sa-ngiampornpanit T, Chuckpaiwong V, Vongthongsri A. A serum- and feederfree technique of culturing human corneal epithelial stem cells on amniotic membrane. Mol Vis 2009; 15: 1294-1302.

51 Nakamura T, Ang LP, Rigby H, Sekiyama E, Inatomi T, Sotozono $\mathrm{C}$ et al. The use of autologous serum in the development of corneal and oral epithelial equivalents in patients with Stevens-Johnson syndrome. Invest Ophthalmol Vis Sci 2006; 47: 909-916.

52 Aoshima K, Baba A, Makino Y, Okada Y. Establishment of alternative culture method for spermatogonial stem cells using knockout serum replacement. PLoS One 2013; 8: e77715.

53 Wagner K, Welch D. Feeder-free adaptation, culture and passaging of human IPS cells using complete knockout serum replacement feeder-free medium. J Vis Exp 2010; 41: 2236.

54 Koizumi N, Rigby H, Fullwood NJ, Kawasaki S, Tanioka H, Koizumi Ket al. Comparison of intact and denuded amniotic membrane as a substrate for cell-suspension culture of human limbal epithelial cells. Graefes Arch Clin Exp Ophthalmol 2007; 245: 123-134.

55 Maliepaard M, Scheffer GL, Faneyte IF, van Gastelen MA, Pijnenborg AC, Schinkel AH et al. Subcellular localization and distribution of the breast cancer resistance protein transporter in normal human tissues. Cancer Res 2001; 61: 3458-3464.

Supplementary Information accompanies this paper on Eye website (http://www.nature.com/eye) 